Article

\title{
Hydrogel Heart Model with Temperature Memory Properties for Surgical Simulation
}

\author{
Hisataka Maruyama, Yuki Yokota *, Keisuke Hosono and Fumihito Arai \\ Department of Micro-Nano Mechanical Science and Engineering, Nagoya University, Furo-cho, \\ Chikusa-ku, Nagoya, Aichi, 464-8601, Japan; hisataka@mech.nagoya-u.ac.jp (H.M.); \\ hosono@biorobotics.mech.nagoya-u.ac.jp (K.H.); arai@mech.nagoya-u.ac.jp (F.A.) \\ * Correspondence: yokota@biorobotics.mech.nagoya-u.ac.jp; Tel.: +81-52-789-5220
}

Received: 14 December 2018; Accepted: 23 February 2019; Published: 4 March 2019

check for updates

\begin{abstract}
The continual development of surgical technology has led to a demand for surgical simulators for evaluating and improving the surgical technique of surgeons. To meet these needs, simulators must incorporate a sensing function into the organ model for evaluating the surgical techniques. However, it is difficult to incorporate a temperature sensor into the conventional cardiac training model. In this study, we propose a heart model for surgical training of cardiac catheter ablation made from hydrogel, which has temperature memory properties. The heart model consists of a photo-crosslinkable hydrogel mixed with an irreversible temperature indicator that exhibits a color change from magenta to colorless at $55^{\circ} \mathrm{C}$. The Young's modulus, electrical resistivity, thermal conductivity, and specific heat capacity of the hydrogel material were evaluated and compared with those of human heart. Furthermore, temperature calibration based on the color of the hydrogel material confirmed that the temperature measurement accuracy of the material is $\pm 0.18{ }^{\circ} \mathrm{C}\left(\right.$ at $56{ }^{\circ} \mathrm{C}$ ). A heart model for catheter ablation was fabricated using the hydrogel material and a molding method, and the color change due to temperature change was evaluated.
\end{abstract}

Keywords: hydrogel model; temperature measurement; surgical simulator; heart model

\section{Introduction}

Progress in medical technology and surgical instruments must be supported by the high surgical skill of surgeons. For this reason, there is a growing need for an artificial organ model and surgical simulator for developing surgical skills [1-3]. Conventionally, animal models with similar structure and characteristics to human organs, VR simulators that use virtual reality, and artificial organ models made of synthetic materials that mimic the structure and characteristics of human organs have been used. Animal models have limitations in their similarities-both structural and in terms of physical properties - to human organs [4-7]. There are also ethical constraints in the use of animal models. While VR simulators can simulate the surgical process without physical models, it is not possible to use specific surgical instruments and interfaces, and registration of new surgical instruments takes time and has a considerable cost [8]. In contrast, artificial organ models have several advantages over other surgical simulators, such as no ethical issues and the possibility of simulating structures and properties similar to those of the target organ. The progress of artificial organ models has been marked and numerous surgical simulators with artificial organ models have been developed and commercialized [9-12]. However, most artificial models do not have sensors for evaluating the skill of the surgeon or the properties of surgical instruments. The integration of measurement functions into artificial organ models without sacrificing the similarity of the structures and properties to those of the target is a promising approach to improving the quality of surgical training by giving quantitative evaluation of the skill of the surgeon or the properties of the surgical instruments [13]. 
Catheter ablation is a procedure for which a surgical simulator with measurement capability is required. In catheter ablation, an electrode is inserted into the target heart blood vessel and ablation energy is applied to the myocardial tissue - the cause of the arrhythmia - via the catheter to cauterize the tissue [9]. The target temperature of the heated area is $55{ }^{\circ} \mathrm{C}$ and treatment by high-frequency ionization to the atrioventricular junction is mainstream [14-16]. Three-dimensional mapping techniques of perfusion catheters and the development of catheters that perfuse the tip of the electrode with cooling water have contributed to improving the safety of catheter ablation. [11,12]. However, catheter ablation at the atrium remains difficult and has a high risk of complications. Particularly serious complications are heart tamponade and esophageal fistula [17]. Cardiac tamponade is the most frequently occurring complication and is caused by atrial puncture with an electrode catheter and excessive cauterization of myocardial tissue. Esophageal fistula has the highest fatality rate and involves the formation of through holes between the left atrium and the esophagus due to excessive cauterization of the posterior wall of the left atrium [18]. Surgical training for catheter ablation using an artificial heart model with a temperature measurement function is, therefore, important for avoiding these risks.

Some approaches to integrating temperature measurement functionality into the artificial heart model are introducing thermocouples, temperature measurement of the model surface using a thermal camera, and integration of temperature sensitive dye. Thermocouples can measure temperature with high sensitivity and high accuracy and thermal cameras can measure the temperature distribution of the model surface in real time. However, these measurement methods have several limitations for temperature measurement in artificial heart models. The integration of thermocouples that are made of metal into the artificial heart model requires cables for measurement, and integration of high thermally-conductive material may change the mechanical, electrical, and thermal properties of the model. The thermal camera cannot measure the temperature of the artificial heart model if it is suspended in water, since the camera measures the temperature at the water surface. In addition, a camera cannot measure the maximum temperature reached inside the artificial heart model.

Our group developed an artificial renal artery with temperature indication. The silicone artery model was impregnated with irreversible temperature-indicating dye [19]. The maximum temperature reached by the artery model was measured by color analysis of the material with image processing. The Young's modulus of the artery model was reproduced similar to the human renal artery. However, the model was made of silicon, and the electrical properties of the model were not similar to those of the human artery. For application in catheter ablation simulation, the material of the artificial organ model should reproduce the electrical resistivity of the target human organ.

In this study, we propose a hydrogel heart model with temperature memory properties for catheter ablation training. The hydrogel heart model mainly consists of a photo-crosslinkable hydrogel that reproduces the Young's modulus and the electrical resistivity of human heart for catheter ablation. The hydrogel heart model is designed to detect areas where the temperature reaches $55^{\circ} \mathrm{C}$ or higher through the color change of the hydrogel. Irreversible temperature-indicating dye is impregnated into the hydrogel material to evaluate the distribution of temperature reached in the hydrogel heart model after training. An irreversible temperature-indicating dye, which changes from magenta to colorless around $55{ }^{\circ} \mathrm{C}$, was used. In addition, it is also possible to observe the areas where the temperature reaches $55^{\circ} \mathrm{C}$ or higher during training. The Young's modulus, electrical resistivity, thermal conductivity, and specific heat capacity of the hydrogel material were measured and compared with those of human heart. The color of the hydrogel material was calibrated with temperature using optical imaging. Finally, we fabricated an artificial heart model of the left atrium with temperature memory functionality using a molding and photo-polymerization method. 


\section{Materials and Methods}

\subsection{Hydrogel Heart Model with Temperature Memory Properties}

Figure 1 shows a schematic diagram of the hydrogel heart model for recording the distribution of maximum temperature reached. The hydrogel heart model has a junction with the pulmonary vein of the left atrium where ablation is conducted in the treatment of arrhythmia. In arrhythmia treatment, the ablation catheter is pressed against the target area to cauterize and block the stray current flow from the pulmonary vein to the left atrium by heating with a high-frequency current. The target area is heated to $55{ }^{\circ} \mathrm{C}$ or higher to cauterize the tissue. The requirements of a heart model for simulating catheter ablation are as follows.

1. Reproduction of the Young's modulus of the human heart;

2. Reproduction of the electrical resistivity of the human heart;

3. Reproduction of the thermal conductivity and specific heat capacity of the human heart;

4. Detection of the areas at which the temperature exceeds $55^{\circ} \mathrm{C}$.

Conventionally, silicone, urethane, and polyvinyl alcohol have been used as materials for artificial heart models. These materials are intended to simulate mechanical properties, such as the shape and Young's modulus of the heart model, and are not subject to the simulation of electrical resistivity or thermal characteristics. Silicone and urethane are insulators, so they cannot be used for surgical training of high-frequency electrical heating.

In this study, hydrogel material was chosen for the heart model to reproduce the Young's modulus, electrical resistivity, and thermal properties of heart tissue. The Young's modulus of the hydrogel heart model was adjusted by altering the concentration of the hydrogel. The electrical resistivity of the hydrogel heart model was adjusted by altering the electrolyte concentration in the hydrogel. The thermal properties were determined from the constitution of the hydrogel material. An irreversible temperature indicator was impregnated into the hydrogel material for detection of the areas of the hydrogel heart model that were heated over $55^{\circ} \mathrm{C}$. A water-soluble polyurethane, with a photo-crosslinkable resin, was used as the main constituent of the hydrogel material. The hydrogel heart model was fabricated using a molding method and photo-polymerization. The color of the hydrogel material changed from magenta to colorless around $55{ }^{\circ} \mathrm{C}$. After the color had changed, it did not recover to magenta. Therefore, the areas where the temperature increased above $55^{\circ} \mathrm{C}$ were permanently indicated by the color change of the hydrogel, allowing for visual inspection. Quantitative measurement of the hydrogel heart model was conducted by cutting out the target areas of the model with a specific thickness, followed by analysis of microscopy images using color information.

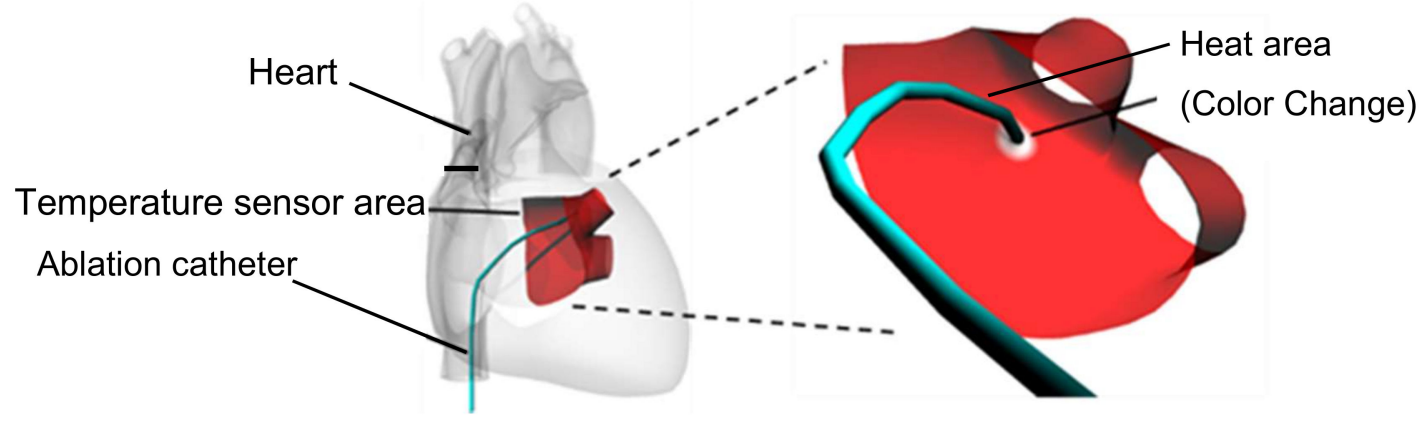

Figure 1. Schematic diagram of the heart model with temperature sensing.

\subsection{Materials for Hydrogel Heart Model Preparation}

The materials used to prepare the hydrogel heart model were water-based polyurethane (PU-W2A, Shin-Nakamura Chemical Co., Ltd., Wakayama, Japan), 20\% polyvinyl alcohol (PVA 424H, KURARAY Co., Ltd., Tokyo, Japan) in aqueous solution, pure water, sodium chloride (Wako Pure Chemical 
Industries, Ltd.), dimethyl sulfoxide (DMSO, Wako Pure Chemical Corporation, Osaka, Japan), photo-initiator (Lithium phenyl (2,4,6-trimethyl-benzoyl) phosphate, Tokyo Chemical Industry Co., Ltd., Tokyo, Japan), and an irreversible temperature indicator solution (METAMO COLOR, PILOT CORPORATION, THE PILOT INK COMPANY, LIMITED, Aichi, Japan). The electrical resistivity was adjusted using the concentration of sodium chloride. The Young's modulus of the heart model was adjusted using the concentration of polyurethane, polyvinyl alcohol, and photo-initiator. The color of the temperature indicator was magenta at room temperature and colorless at temperatures above $55{ }^{\circ} \mathrm{C}$. This color change did not recover when the temperature recovers to room temperature. Table 1 shows the composition of each material used for the hydrogel heart model.

Table 1. Composition of the hydrogel material.

\begin{tabular}{ccccccc}
\hline Thermo-Sensitive Dye & Polyurethane & $\mathbf{2 0} \% \mathbf{P V A}$ & DI Water & $\mathbf{N a C l}$ & DMSO & Photo-Initiator \\
\hline $10 \mathrm{~g}$ & $20 \mathrm{~g}$ & $20 \mathrm{~g}$ & $150 \mathrm{~g}$ & $1.35 \mathrm{~g}$ & $10 \mathrm{~g}$ & $200 \mathrm{mg}$ \\
\hline
\end{tabular}

\section{Evaluation of Hydrogel Material}

\subsection{Young's Modulus of the Hydrogel Material}

The Young's modulus of the hydrogel material was evaluated by tensile tests using Equation (1).

$$
E=\frac{\sigma}{\varepsilon}=\frac{F}{A} \cdot \frac{L_{0}}{d L}
$$

where $E$ is Young's modulus, $\sigma$ is stress, and $\varepsilon$ is strain, $F$ is the force input to the specimen, $A$ is the cross-sectional area of the specimen, $L_{0}$ is the initial length of the specimen, and $d L$ is the displacement of the specimen. A specimen of the hydrogel material with a thickness of $2 \mathrm{~mm}$ was fabricated using a dumbbell cutter (SDMP-1000, DUMBBELL Co., Ltd, Saitama, Japan). The tensile test was carried out using a tensile tester EZ-LX (Shimadzu corporation, Kyoto, Japan), and the Young's modulus was calculated using the result of the tensile test and the cross-sectional area and strain of the specimen.

Figure 2 shows the tensile test of the hydrogel material. The Young's Modulus of the hydrogel material was calculated using the value of $10 \%$ strain condition of stress-strain curve in Figure 2 and Equation (1). From the results of the tensile test using four specimens made of the hydrogel material, shown in Table 1, the Young's modulus was measured to be $20.0 \pm 3.3 \mathrm{kPa}$, which is similar to the value of human heart from the literature shown in Table 2 [20-22].

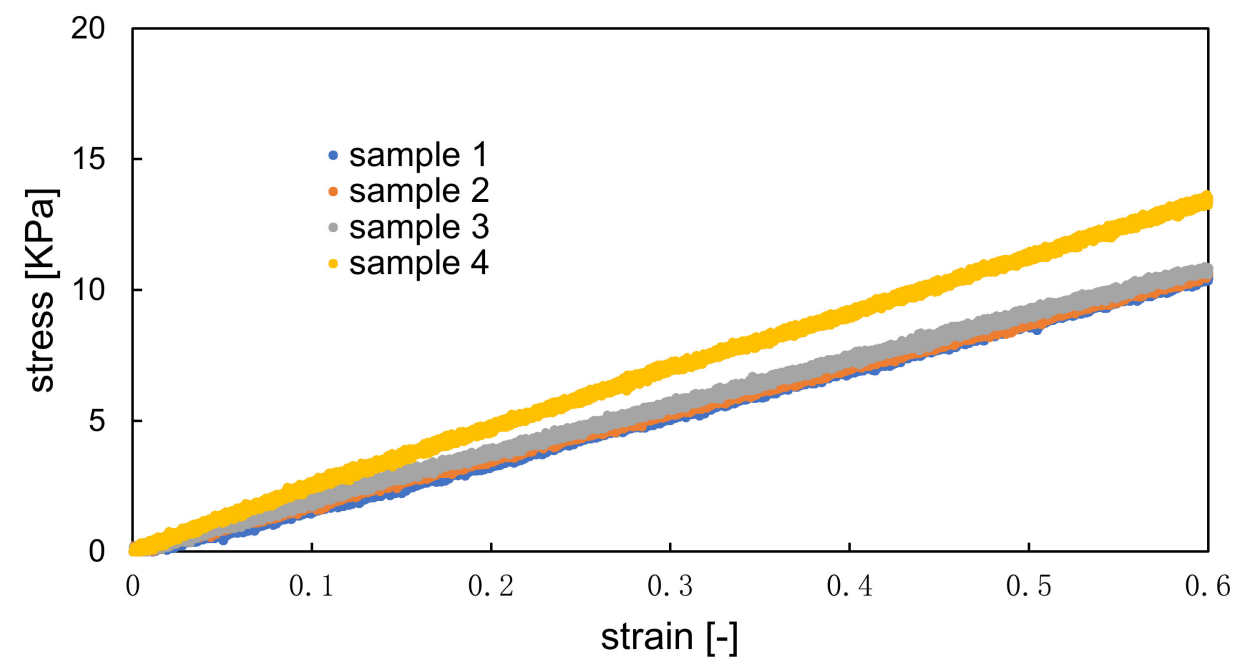

Figure 2. Tensile test of hydrogel material. 
Table 2. Comparison of the properties of the hydrogel model and human heart.

\begin{tabular}{ccc}
\hline Parameter & $\begin{array}{c}\text { Human Heart } \\
\text { (Literature) }\end{array}$ & Heart Model \\
\hline Young's modulus $[\mathrm{kPa}]$ & $20.3[20]$ & 20.0 \\
Electric resistivity $[\Omega \cdot \mathrm{cm}]$ & $132[21]$ & 98.1 \\
Thermal conductivity $[\mathrm{W} / \mathrm{m} \cdot \mathrm{K}]$ & $0.47[22]$ & 1.33 \\
Specific heat capacity $[\mathrm{J} / \mathrm{g} \cdot \mathrm{K}]$ & $3.55[22]$ & 4.0 \\
\hline
\end{tabular}

\subsection{Electrical Resistivity of the Hydrogel Material}

The electrical resistivity of the hydrogel material was evaluated using Equation (2).

$$
R=\rho \frac{l}{M}
$$

where $R$ is the electrical resistance of the hydrogel material, $\rho$ is the electrical resistivity of the hydrogel material, $l$ is the length of the hydrogel material, and $M$ is the cross-sectional area of the hydrogel material. An Impedance Analyzer ZA 5403 (NF corporation, Kanagawa, Japan) was used to measure the electrical resistance. The size of the specimen was $2 \mathrm{~mm}$ in width and $2 \mathrm{~mm}$ in thickness. The length was measured for each specimen. The frequency for measuring the electrical resistance was $100 \mathrm{~Hz}$ to $10 \mathrm{MHz}$. The electrical resistivity was measured for hydrogel materials prepared with different concentrations of sodium chloride $(0 \mathrm{wt} \%, 0.64 \mathrm{wt} \%$, and $1.27 \mathrm{wt} \%)$ to evaluate the effect of sodium chloride concentration on electrical resistivity (Figure 3). The hydrogel material containing $0.64 \mathrm{wt} \%$ sodium chloride is the same constitute shown in Table 1 . The electrical resistivity of the human heart in the literature is $132 \Omega \cdot \mathrm{cm}$ at $1 \mathrm{MHz}$, as shown in Table 2 [20-22]. The average value of the electrical resistivity at $1 \mathrm{MHz}$ was $3.85 \times 10^{2} \Omega \cdot \mathrm{cm}$ in $0 \mathrm{wt} \%$ sodium chloride. The average value of the electrical resistivity at $1 \mathrm{MHz}$ decreased to $43.5 \Omega \cdot \mathrm{cm}$ in $1.27 \mathrm{wt} \%$ sodium chloride. These results show that the electrical resistivity can be controlled by adjusting the concentration of sodium chloride. In this study, the concentration of sodium chloride used was $0.64 \mathrm{wt} \%$ and the average electrical resistivity at $1 \mathrm{MHz}$ was $98.1 \Omega \cdot \mathrm{cm}$. This value is similar to the electrical resistivity of human heart tissue [22-24].

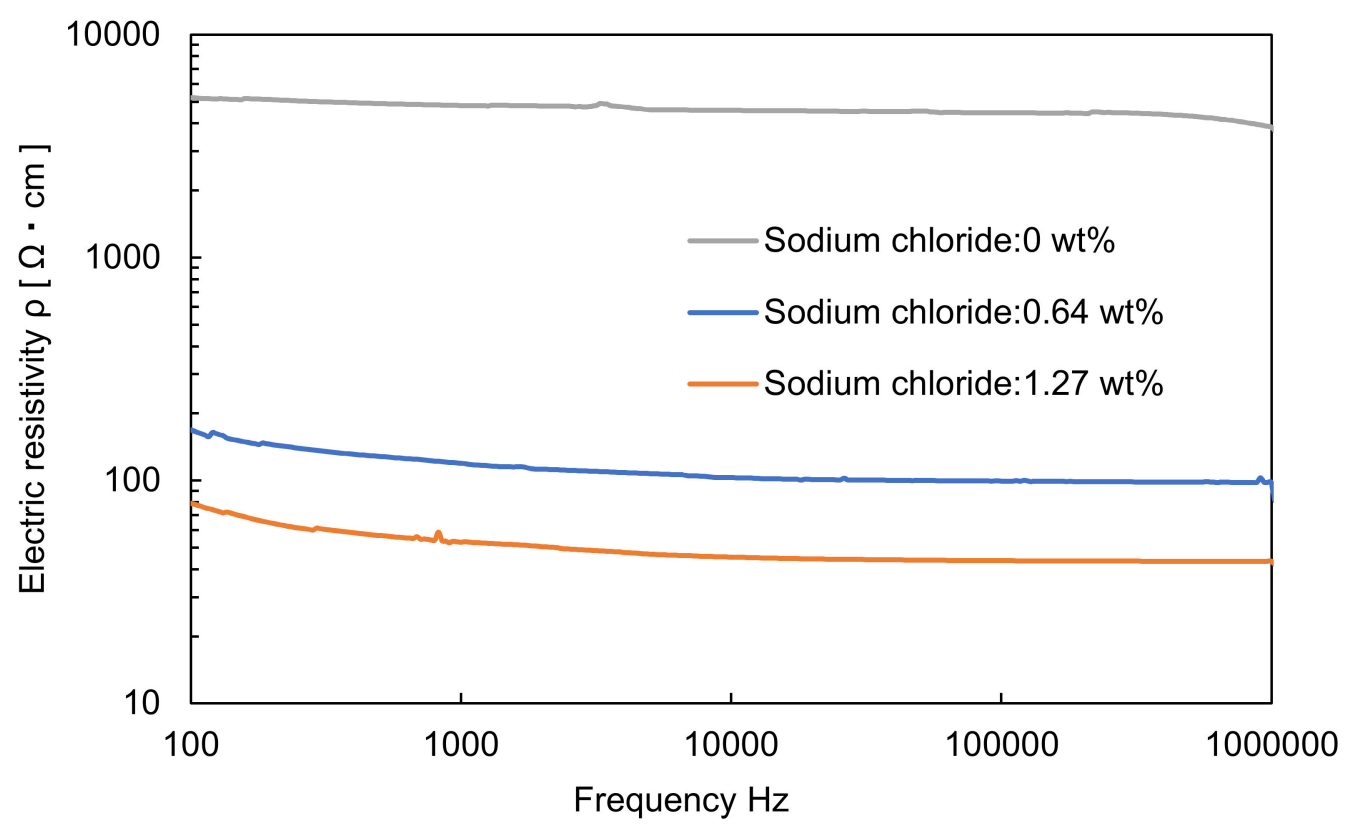

Figure 3. Hydrogel electrical resistivity for different sodium chloride concentrations. 


\subsection{Thermal Properties of the Hydrogel Material}

The thermal properties of the hydrogel material were evaluated by determining the thermal conductivity and specific heat capacity. To measure thermal conductivity, the laser flash, steady state, or heat ray methods can be applied. In this study, the heat ray method, which can measure within a short time period, was used to reduce the influence of drying of the hydrogel material. Measurement of the thermal conductivity was carried out using a thermal conductivity measuring device TCi (Rigaku Corporation, Tokyo, Japan), and the size of the hydrogel specimen was $33 \mathrm{~mm}$ in diameter and $1 \mathrm{~cm}$ in height. The measured thermal conductivity was $1.33 \mathrm{~W} / \mathrm{m} \cdot \mathrm{k}$, as shown in Table 2 [20-22]. This value was higher than the thermal conductivity of the human heart.

The specific heat capacity of the hydrogel material was measured using heat flux differential scanning calorimetry. The temperature difference between the test material and a reference substance was measured while varying the temperature of a sample composed of the test material and reference substance. The specific heat capacity of the sample was calculated from the measured data. A DSC-60A (Shimadzu corporation, Kyoto, Japan) was used for measurement. To prevent the effect of drying, the sample was introduced into a chamber cell and sealed. The range of temperature measurement was $30-70{ }^{\circ} \mathrm{C}$ and the heating rate was $1{ }^{\circ} \mathrm{C} / \mathrm{min}$. Figure 4 shows experimental data for 3 specimens made of the hydrogel materials shown in Table 1 . The average value of specific heat capacity at $56{ }^{\circ} \mathrm{C}$ was $4.1 \mathrm{~J} /(\mathrm{g} \cdot \mathrm{K})$, and this value was similar to that of human heart, as shown in Table 2 [20-22].

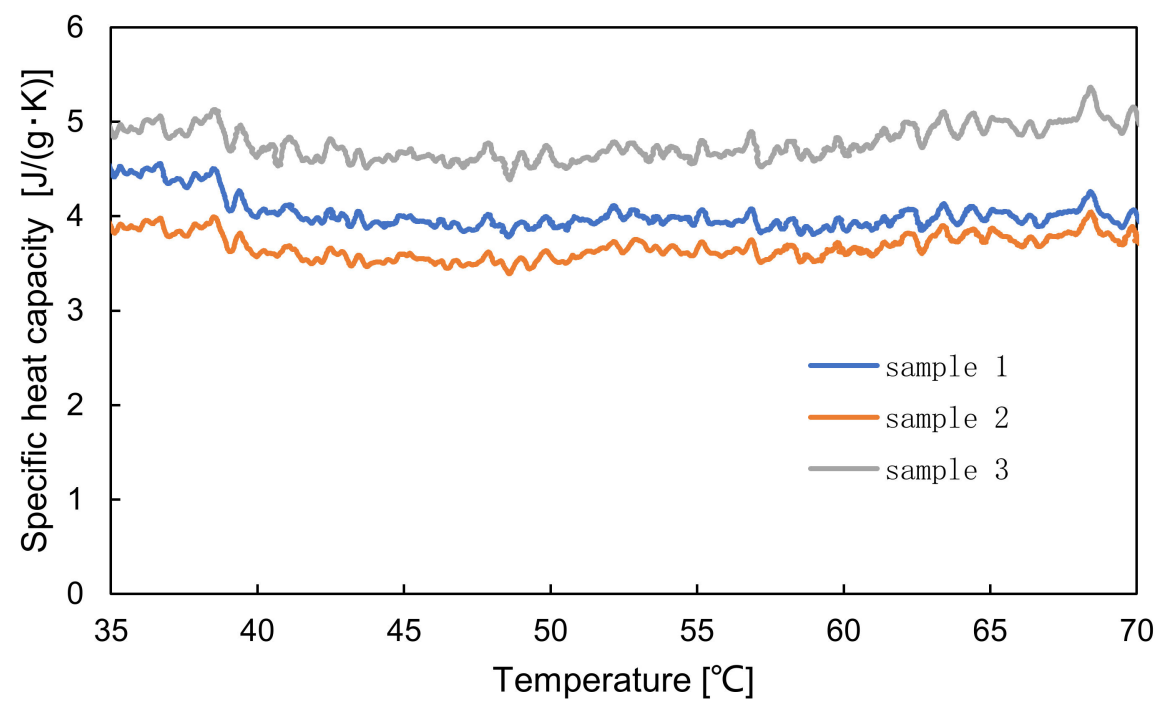

Figure 4. Specific heat capacity of the hydrogel material.

\subsection{Calibration of Hydrogel Material Color with Temperature}

The area of the hydrogel heart model heated over $55^{\circ} \mathrm{C}$ was determined from the color of the hydrogel. Calibration of hydrogel material color with temperature reached was performed using the experimental setup shown in Figure 5. Images of the hydrogel material were acquired with a CMOS color camera (GS3-U3-23S6C-C, FLIR Systems, Inc., Wilsonville, OR, USA), using an objective lens (MV PLAPO 1X, Olympus corporation, Tokyo, Japan) with a magnification of 1 in a stereomicroscope (MVX 10, Olympus Corporation, Tokyo, Japan). LED lighting (LED-R72, ARMSSYSTEM corporation, Tokyo, Japan) was used as the light source. To eliminate the influence of the thickness of the specimen, the thickness was fixed at $2 \mathrm{~mm}$. A water bath type thermostatic chamber (TR-3A, As One corporation, Osaka, Japan) was used for heating the hydrogel material, and the water temperature was measured with a thermocouple (CTH-1365, CUSTOM corporation, Tokyo, Japan). The temperature of the water in the thermal bath was controlled for heating the hydrogel material. The hydrogel material was sink in the thermal bath, and kept for $5 \mathrm{~min}$ to make the temperature of the hydrogel material the same as that of the water in the thermal bath. 


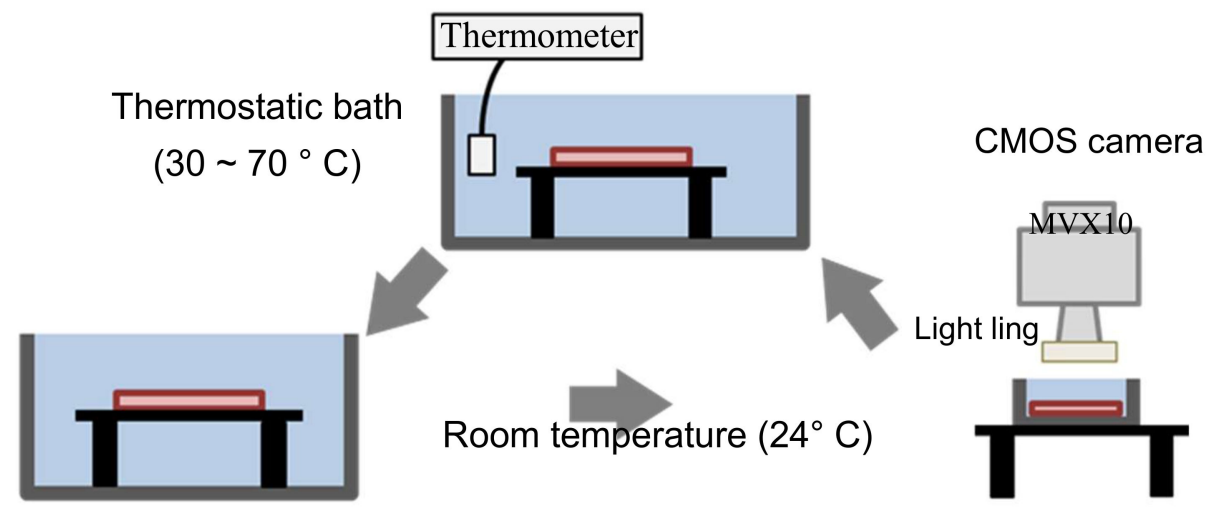

Figure 5. Schematic diagram of the calibration process.

The acquired image is represented in the RGB color space. In the RGB color space, brightness information is included in the R, G, and B values of each pixel. Therefore, measurement using the RGB color space is influenced by fluctuations of the illumination light. To eliminate this effect, the RBG color space was converted to the $\mathrm{YCrCb}$ color space using Equation (3) to separate the brightness information and color information in each pixel.

$$
\left[\begin{array}{c}
Y \\
C r \\
C b
\end{array}\right]=\left[\begin{array}{ccc}
0.299 & 0.587 & 0.114 \\
0.500 & -0.419 & -0.081 \\
-0.169 & -0.331 & 0.500
\end{array}\right]\left[\begin{array}{l}
R \\
G \\
B
\end{array}\right]
$$

$R$ is red, $G$ is green, $B$ is blue, $Y$ is brightness, $C r$ is red color difference, and $C b$ is blue color difference. The temperature calibration process for the hydrogel material is shown in Figure 5.

1. The hydrogel material was immersed in the thermostatic chamber at $30^{\circ} \mathrm{C}$ for $5 \mathrm{~min}$;

2. The hydrogel material was removed from the chamber and put in water at $24{ }^{\circ} \mathrm{C}$ for $5 \mathrm{~min}$;

3. The hydrogel material was moved from the water to the microscope and the image was acquired;

4. The above process was repeated from $30-70{ }^{\circ} \mathrm{C}$. In the range $55-60^{\circ} \mathrm{C}$, temperature was changed in $0.5^{\circ} \mathrm{C}$ intervals.

Figure 6 shows images of the hydrogel material in the temperature range $55-58^{\circ} \mathrm{C}$. The color of the hydrogel material changed between 55.5 and $56.5^{\circ} \mathrm{C}$. Figure 7 shows the results of the calibration of $\mathrm{Cr}$ with temperature from 30 to $70{ }^{\circ} \mathrm{C}$. The calibration results were fitted using the sigmoid function shown in Equation (4). Table 3 shows parameters as a result of calibration to the sigmoid function.

$$
T_{\max }=c+\frac{1}{b} \ln \frac{C r-d}{a}
$$

where $T_{\max }$ is the measured temperature of the water in the thermal bath, and $a, b, c$, and $d$ are parameters of the sigmoid function. The calibration result confirmed that the temperature reached by the hydrogel material can be measured with high accuracy $\pm 0.18^{\circ} \mathrm{C}$ at $56^{\circ} \mathrm{C}$.
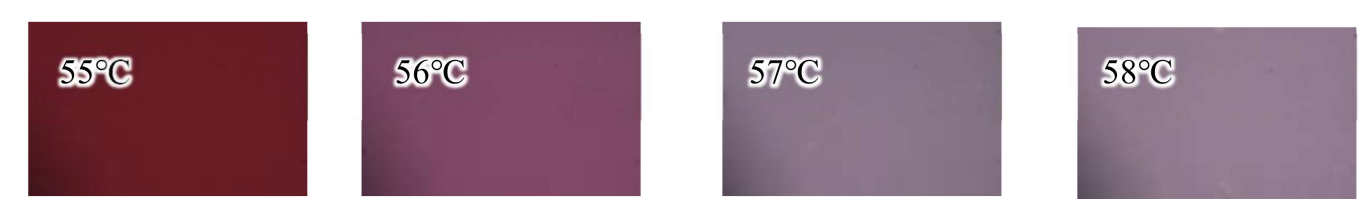

Figure 6. Color of the hydrogel material at each temperature. 


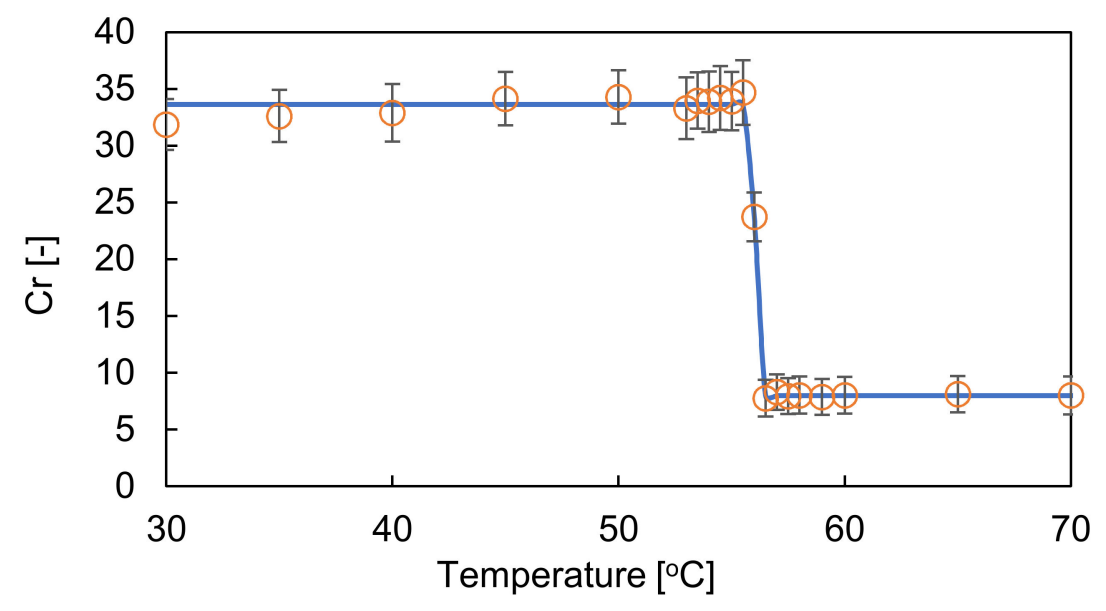

Figure 7. Calibration of color with temperature.

Table 3. Parameters of sigmoid function.

\begin{tabular}{cccc}
\hline $\boldsymbol{a}$ & $\boldsymbol{b}$ & $\boldsymbol{c}$ & $\boldsymbol{d}$ \\
\hline 20.0 & 7.98 & 25.6 & 56.0 \\
\hline
\end{tabular}

\section{Fabrication of Hydrogel Heart Model with Temperature Memory Functionality}

As a hydrogel heart model, we fabricated part of the left atrium with the pulmonary vein. This area is a target region in catheter ablation for treatment of arrhythmia. A molding method and photo-polymerization were used for fabrication. Polydimethylsiloxane (PDMS), which is a transparent silicone elastomer, was used as a mold for the heart model. The photo-crosslinkable hydrogel material was polymerized using ultraviolet (UV) illumination as PDMS transmits UV light. In addition, an oxygen inhibition layer on the inner wall surface of the PDMS was formed, since PDMS has high oxygen permeability. This oxygen inhibition layer inhibits the photo-polymerization, and prevents polymerized hydrogel adhering to the PDMS mold. Therefore, the fabricated hydrogel heart model can be easily removed from the PDMS mold.

Figure 8 shows the fabrication process for the hydrogel heart model. The 3D data of the cardiac model was generated from CT scan data of the heart.

1. A resin model of a heart model was fabricated from 3D data using a commercial 3D printer.

2. The resin model was introduced into uncured PDMS.

3. After curing the PDMS, the resin model was removed to make a hollow PDMS mold.

4. Unpolymerized hydrogel material was introduced into the PDMS mold.

5. The hydrogel material is irradiated with UV $(375-405 \mathrm{~nm})$ light from the periphery of the PDMS mold for photo-polymerization of the hydrogel.

6. The polymerized hydrogel heart model was removed from the PDMS mold.

A DLP type 3D printer (M3DS-SA5, MITS Electronics corporation, Tokyo, Japan) was used to fabricate the resin heart model. UV Curing Chamber (XYZ printing incorporated, Tokyo, Japan) was used for UV illumination. The wavelength of the UV LED was 375-405 nm. Power of UV LED was $180 \mathrm{~mW}$ at $400 \mathrm{~nm}$. Emission exposure time was $30 \mathrm{~s}$. The fabricated hydrogel heart model is shown in Figure 9a. When the lower half of the hydrogel heart model was immersed in hot water at $60{ }^{\circ} \mathrm{C}$ for $30 \mathrm{~s}$, the immersed area changed color from magenta to colorless, as shown in Figure $9 \mathrm{~b}$. After immersing the hydrogel heart model to hot water, the color of the hydrogel heart model changed from magenta to colorless gradually. The color of the immersed area of the hydrogel heart model completely changed within $30 \mathrm{~s}$. This discoloration was maintained when the temperature was subsequently reduced. These findings confirmed the effectiveness of the hydrogel heart model with temperature memory functionality. 


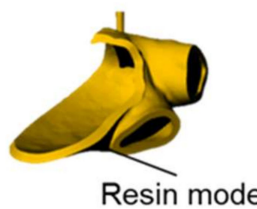

(a)

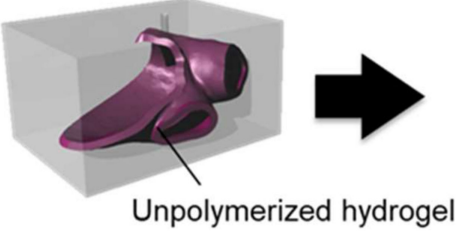

(d)

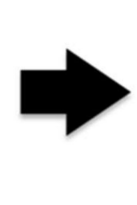

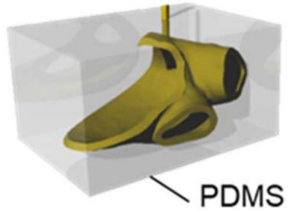

(b)

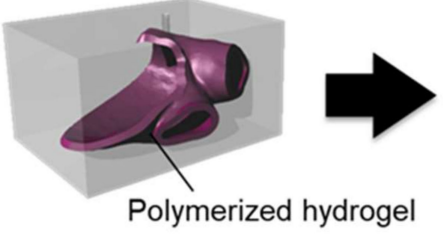

(e)

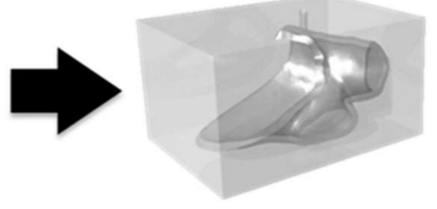

(c)

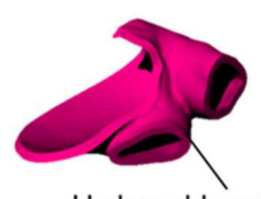

Hydrogel heart model

(f)

Figure 8. Hydrogel heart model fabrication process. (a) Fabrication of a resin heart model, (b) introduction of the resin model into PDMS, (c) removal of the resin model from the polymerized PDMS, (d) introduction of uncured hydrogel material, (e) photo-polymerization of the hydrogel material by UV irradiation, and (f) extraction of the cured hydrogel heart model from the PDMS mold.

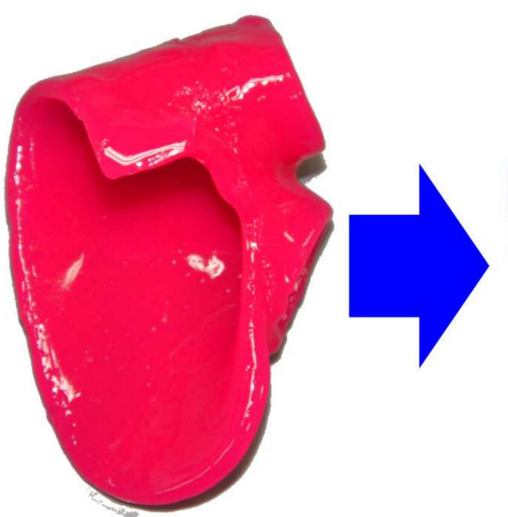

(a)

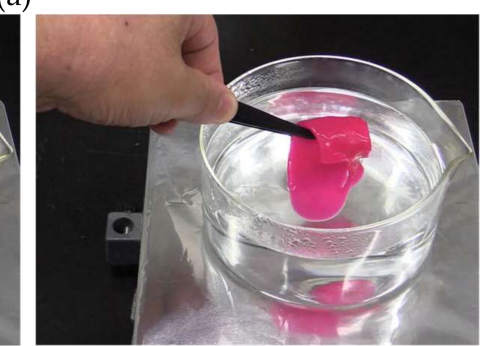

(d)

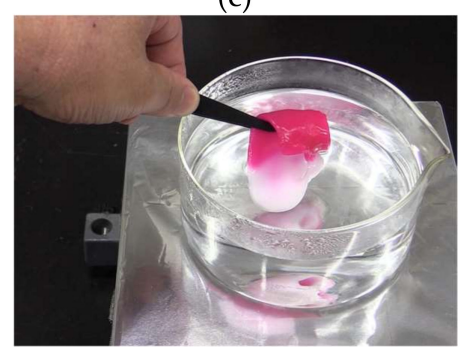

(f)

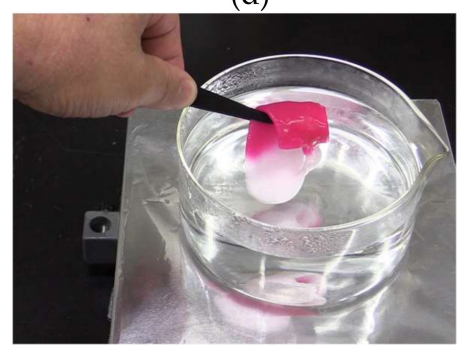

(g)

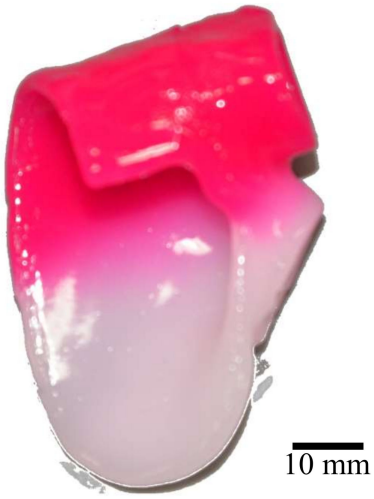

(b)

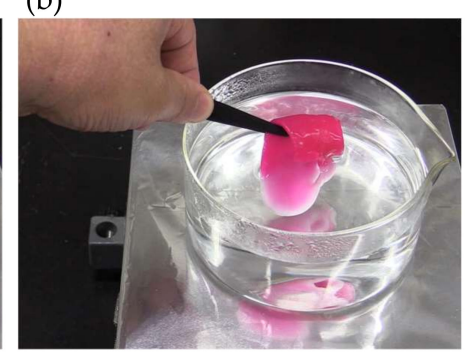

(e)

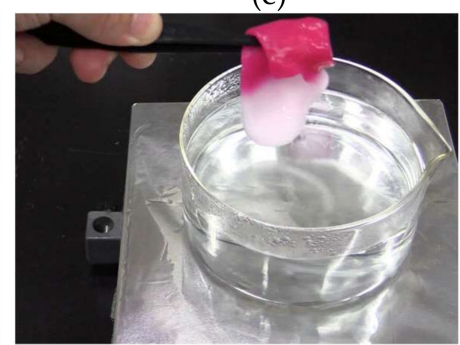

(h)

Figure 9. Photographs of the fabricated hydrogel heart model. (a) Before heating, and (b) after heating the lower part of the model at $60^{\circ} \mathrm{C}$. (c) Before immersing the hydrogel heart model. (d) Immersing the hydrogel heart model, (e) after $10 \mathrm{~s}$, (f) after $20 \mathrm{~s}$, (g) after $30 \mathrm{~s}$, and (h) picking up the hydrogel heart model. 


\section{Discussion}

In this study, we developed a hydrogel heart model that reproduces the Young's modulus, electrical resistivity, and thermal characteristics of human heart tissue for surgical training of catheter ablation. As shown in Table 3, we succeeded in reproducing the characteristics of human heart, such as Young's modulus, electrical resistivity, and specific heat capacity. However, the thermal conductivity of the hydrogel material was three times higher than that of human heart tissue. Since the thermal conductivity of PVA is $\sim 0.3 \mathrm{~W} / \mathrm{mK}$, that of the water-soluble polyurethane is $0.2 \mathrm{~W} / \mathrm{mK}$, and that of water is $0.58 \mathrm{~W} / \mathrm{mK}$, the thermal conductivity of the temperature indicator is thought to be much higher than that of human tissue [23,24]. The thermal conductivity of the hydrogel should, therefore, be reduced to more closely simulate the thermal conductivity of human heart [19]. One solution is to introduce other low thermal conductivity materials while considering their effect on the other properties, such as Young's modulus, electrical resistivity, and specific heat capacity. Adjusting the thermal conductivity of the hydrogel material is an aim of the future work. We adjusted the physical parameter of the hydrogel model, as shown in Table 1, by trial and error. When we changed the constitute of the hydrogel, we faced the coupling problem of several parameters of the hydrogel material. For example, increase of the concentration of water-soluble PU resulted in increase of Young's modulus and decrease of thermal conductivity of the model, since thermal conductivity of water-soluble PU is lower than that of the hydrogel material. Construction of a design theory considering such coupling problems is a future task.

In this work, the areas of the hydrogel heart model that reached the target temperature were indicated by a permanent color change of the hydrogel owing to the inclusion of an irreversible temperature indicator that changes color from magenta to colorless at temperatures over $55^{\circ} \mathrm{C}$. The accuracy of the temperature measurement in the discolored area was $\pm 0.18^{\circ} \mathrm{C}$ (at $56^{\circ} \mathrm{C}$ ), which enabled highly accurate analysis of the areas of the hydrogel that exceeded $55^{\circ} \mathrm{C}$. In addition, the distribution of the areas inside the model heated over $55^{\circ} \mathrm{C}$ could be measured by taking sections. This hydrogel model with temperature indication could be applied to different simulations by changing the temperature indicator. For measurement over a wide temperature range, indication could be achieved by mixing different indicators [19]. In addition, a reversible temperature indicator could be used for real-time monitoring of temperature variation. As described above, various applications could be realized by changing the temperature indicator for the hydrogel material according to the application.

\section{Conclusions}

In this study, we proposed a hydrogel heart model, which has temperature memory properties, for surgical training of cardiac catheter ablation. The model reproduces the physical, electrical, and thermal characteristics of heart tissue, and the areas of the model heated over $55^{\circ} \mathrm{C}$ were recorded. A tensile test showed that the Young's modulus of the hydrogel material was similar to that of human heart tissue. For high frequency heating with an ablation catheter, the electrical resistivity was adjusted to a value close to that of the human heart using a hydrophilic photo-crosslinkable hydrogel and electrolyte. Thermal conductivity and specific heat capacity were evaluated to establish the thermal properties of the hydrogel material. The specific heat capacity was similar to that of human heart. However, the thermal conductivity was higher than that of human heart tissue and adjustment of the thermal conductivity will form part of our future work. The color of the hydrogel material changed from magenta to colorless at temperatures over $55^{\circ} \mathrm{C}$-the target temperature of catheter ablation - to give temperature memory properties. The color change of the hydrogel material was introduced using an irreversible temperature indicator. The evaluation of the area of the hydrogel model heated over $55^{\circ} \mathrm{C}$ was performed by visual observation and image analysis. The color of the hydrogel material was calibrated with the temperature reached by image analysis using the $\mathrm{YCrCb}$ color space, and successfully measured an accuracy at $56^{\circ} \mathrm{C}$ of $\pm 0.18^{\circ} \mathrm{C}$. The hydrogel heart model was fabricated using a molding method and photo-polymerization based on CT data of the left atrium of a patient. 
Since photo-polymerization was achieved by irradiating with UV light for $1 \mathrm{~min}$, it is possible to fabricate a heart model in a short time. Color change due to heating of the hydrogel heart model was demonstrated.

In future work we will adjust the thermal conductivity of the model to that of the human heart and simulate catheter ablation with high-frequency current to confirm the effectiveness of our hydrogel model as a surgical simulator. This surgical model with sensing functionality will make a significant contribution to the medical field.

Author Contributions: Conceptualization, K.H., H.M. and F.A.; Methodology, Y.Y., K.H., H.M. and F.A.; Software, Y.Y., K.H. and H.M.; Validation, Y.Y., K.H., H.M. and F.A.; Formal analysis, Y.Y., K.H. and H.M.; Investigation, Y.Y., K.H., H.M. and F.A.; Resources, Y.Y., K.H., H.M. and F.A.; data Curation, Y.Y. and K.H.; Writing-original draft preparation, Y.Y. and H.M.; Writing-review and editing, Y.Y., H.M. and F.A.; Visualization, Y.Y., H.M. and F.A.; Supervision, F.A.; Project administration, F.A.; Funding acquisition, F.A.

Funding: This research was supported by the Cross-ministerial Strategic Innovation Promotion Program (SIP) of the Ministry of Agriculture, Forestry, and Fisheries of Japan.

Acknowledgments: The 3D human heart data were provided by FANE-Biomedical. METAMO COLOR was provided by PILOT CORPORATION and THE PILOT INK COMPANY, LIMITED. Rigaku corporation supported to measure thermal conductivity of the hydrogel material.

Conflicts of Interest: The authors declare no conflict of interest.

\section{References}

1. Aggarwal, R.; Darzi, A. Surgical Research Review From scalpel to simulator: A surgical journey. Surgery 2008, 145, 1-4. [CrossRef] [PubMed]

2. Scott, D.J.; Dunnington, G.L. The New ACS/APDS Skills Curriculum: Moving the Learning Curve Out of the Operating Room. J. Gastrointest. Surg. 2008, 12, 213-221. [CrossRef] [PubMed]

3. Wignall, G.R.; Denstedt, J.D.; Preminger, G.M.; Cadeddu, J.A.; Pearle, M.S.; Sweet, R.M.; McDougall, E.M. Surgical Simulation: A Urological Perspective. J. Urol. 2008, 179, 1690-1699. [CrossRef] [PubMed]

4. Saifi, J.; Chang, B.B.; Paty, P.S.K.; Kaufrnan, J.; Leather, R.P.; Shah, D.M. An animal model for instructing and the study of in situ arterial bypass. J. Vasc. Surg. 1990, 12, 4-6. [CrossRef]

5. Shinbane, J.S.; Wood, M.A.; Jensen, D.N.; Ellenbogen, K.A.; Fitzpatrick, A.P.; Scheinman, M.M. Tachycardia-Induced Cardiomyopathy: A Review of Animal Models and Clinical Studies. J. Am. Coll. Cardiol. 1997, 29, 709-715. [CrossRef]

6. Patterson, E.J.; Scudamore, C.H.; Owen, D.A.; Nagy, A.G.; Buczkowski, A.K. Radiofrequency Ablation of Porcine Liver In Vivo Effects of Blood Flow and Treatment Time on Lesion Size. Ann. Surg. 1998, 227, 559-565. [CrossRef] [PubMed]

7. Dorrance, H.R.; Oien, K.; Dwyer, P.J.O. Effects of laparoscopy on intraperitoneal tumor growth and distant metastases in an animal model. Surgery 1999, 126, 35-40. [CrossRef] [PubMed]

8. Satava, R.M. Virtual reality surgical simulator. Surg. Endosc. 1993, 7, 203-205. [CrossRef] [PubMed]

9. Scheinman, M.M.; Morady, F.; Hess, D.S.; Gonzalez, R. Catheter-induced ablation of the atrioventricular junction to control refractory supraventricular arrhythmias. JAMA 1982, 248, 851-855. [CrossRef] [PubMed]

10. Gallagher, J.J.; Svenson, R.H.; Kasell, J.H.; German, L.D.; Bardy, G.H.; Broughton, A.; Critelli, G. Catheter technique for closed-chest ablation of the atrioventricular conduction system. N. Engl. J. Med. 1982, 306, 194-200. [CrossRef] [PubMed]

11. Ben-Haim, S.A.; Osadchy, D.; Scnuster, I.; Gepstein, L.; Hayam, G.; Josephson, M.E. Nonfluoroscopic, in vivo navigation and mapping technology. Nat. Med. 1996, 2, 1393-1395. [CrossRef] [PubMed]

12. Gepstein, L.; Hayam, G.; Ben-Haim, S.A. A novel method for nonfluoroscopic catheter-based electroanatomical mapping of the heart: In vitro and in vivo accuracy results. Circulation 1997, 95, 1611-1622. [CrossRef] [PubMed]

13. Ikeda, S.; Arai, F.; Fukuda, T.; Negoro, M.; Irie, K. An In Vitro Patient-Specific Biological Model of the Cerebral Artery Reproduced with a Membranous Configuration for Simulating Endovascular Intervention. J. Robot. Mechatron. 2005, 17, 327-334. [CrossRef]

14. Lavergne, T.H.; Guize, L.; Le Heuzey, J.Y.; Carcone, P.; Geslin, J.; Cousin, M.T. Closed-chest atrioventricular junction ablation by high-frequency energy transcatheter desiccation. Lancet 1986, 2, 858-859. [CrossRef] 
15. Davis, M.J.; Murdock, C. Radiofrequency catheter ablation of refractory ventricular tachycardia. Pacing Clin. Electrophysiol. 1988, 11, 725-729. [CrossRef] [PubMed]

16. Borggrefe, M.; Budde, T.; Podczeck, A.; Breithardt, G. High frequency alternating current ablation of an accessory pathway in humans. J. Am. Coll. Cardiol. 1987, 10, 576-582. [CrossRef]

17. Cappato, R.; Calkins, H.; Chen, S.A.; Davies, W.; Iesaka, Y.; Kalman, J.; Kim, Y.H.; Klein, G.; Natale, A.; Packer, D.; et al. Prevalence and causes of fatal outcome in catheter ablation of atrial fibrillation. J. Am. Coll. Cardiol. 2009, 53, 1798-1803. [CrossRef] [PubMed]

18. Martinek, M.; Bencsik, G.; Aichinger, J.; Hassanein, S.; Schoefl, R.; Kuchinka, P.; Nesser, H.J.; Purerfellner, H. Esophageal damage during radiofrequency ablation of atrial fibrillation: Impact of energy settings, lesion sets, and esophageal visualization. J. Cardiovasc. Electrophysiol. 2009, 20, 726-733. [CrossRef] [PubMed]

19. Hayakwa, T.; Maruyama, H.; Watanabe, T.; Arai, F. Three-Dimensional Blood Vessel Model with Temperature-Indicating Function for Evaluation of Thermal Damage During Surgery. Sensors 2018, 18, 345. [CrossRef] [PubMed]

20. Sommer, G.; Schriefl, A.J.; Andrä, M.; Sacherer, M.; Viertler, C.; Wolinski, H.; Holzapfel, G.A. Biomechanical properties and microstructure of human ventricular myocardium. Acta Biomater. 2015, 24, 172-192. [CrossRef] [PubMed]

21. Geddes, L.A.; Baker, L.E. The specific resistance of biological materials-A compendium of data for the biomedical engineer and physiologist. Med. Biol. Eng. 1967, 5, 271-293. [CrossRef] [PubMed]

22. Werner, J.; Buse, M. Temperature profiles with respect to inhomogeneity and geometry of the human body. J. Appl. Physiol. 1988, 65, 1110-1118. [CrossRef] [PubMed]

23. Cai, D.; Song, M. Latex technology as a simple route to improve the thermal conductivity of a carbon nanotube/polymer composite. Carbon 2008, 46, 2107-2112. [CrossRef]

24. Xie, X.; Li, D.; Tsai, T.-H.; Liu, J.; Braun, P.V.; Cahill, D.G. Thermal Conductivity, Heat Capacity, and Elastic Constants of Water-Soluble Polymers and Polymer Blends. Macromolecules 2016, 494, 972-978. [CrossRef]

(C) 2019 by the authors. Licensee MDPI, Basel, Switzerland. This article is an open access article distributed under the terms and conditions of the Creative Commons Attribution (CC BY) license (http:/ / creativecommons.org/licenses/by/4.0/). 